\title{
Biodegradation of Blend Films PVA/PVC, PVA/PCL in Soil and Soil with Landfill Leachate
}

\author{
Adriana de Campos ${ }^{1}$, José Carlos Marconato ${ }^{1}$ and Sandra Mara Martins-Franchetti ${ }^{1 *}$ \\ ${ }^{I}$ Departamento de Bioquímica e Microbiologia; Instituto de Biociências; Universidade Estadual Paulista Júlio de \\ Mesquita Filho; Av. 24-A, 1515; C. P.: 199; 13506-900; Rio Claro - SP - Brasil
}

\begin{abstract}
This study investigated the biodegradation of blends films of poly(vinyl alcohol)/poly(vinyl chloride) (PVA/PVC) and poly(vinyl alcohol)/poly(caprolactone) (PVA/PCL) blends films prepared with dimethylformamide under a variety of conditions by respirometry, spectrophotometry (FTIR), scanning electron microscopy (SEM), and contact angle. The films were buried in the garden soil and in the soil mixed with the landfill leachate for 120 days at $28^{\circ} \mathrm{C}$. Significant levels of biodegradation were achieved in fairly short incubation times in the soil. The results indicated that PVA was the most biodegradable film in the soil and in the soil with the leachate.
\end{abstract}

Key words: synthetic polymers, biodegradable polymers, soil, poly(vinyl alcohol), poly(caprolactone), poly(vinyl chloride)

\section{INTRODUCTION}

The volume of plastic waste worldwide continues to grow at alarming rates every year and the time required for its biodegradation is often unknown (Rosa et al., 2002; Takasu et al., 2002; César et al., 2009). Polymers and synthetic blends are largely inert and resistant to environmental degradation. Successful improvements of these materials in terms of protective properties and low-cost packaging devices have resulted in an enormous increase in the use of the polymer and in its contribution to waste (20 to $30 \%$ of total waste) (Huang et al., 1995; Rosa et al., 2002; Darwis et al., 1999). It has been estimated that the plastics make up 14 million tons of municipal solid waste/year and 100,000 tons/year in the ocean (Reddy et al., 2003). Hence, to reduce the dependence on the landfills, interest has increasingly focused on the production and use of biodegradable polymers (César et al., 2009; Wu et al., 2003). Among the biodegradable synthetic polymers, the aliphatic polymers, including the poly ( $\varepsilon$-caprolactone) (PCL) and a blend of poly(vinyl alcohol) with starch, are considered promising materials (Darwis et al., 1999). The advantage of blending the polymers is that the properties of commercially available polymers can be modified by an inexpensive route (Amass et al., 1998; Pospisil et al., 1999; Karal et al., 1997).

Biodegradation generally allows for cheaper final disposal of plastic waste through composting and returns the polymer into the natural carbon cycle. By definition, biodegradable polymers are those that are degraded into carbon dioxide, water, and biomass as a result of the action of living organisms or enzymes. The rate of degradation and polymer crystallinity are important factors

*Author for correspondence: samaramf@rc.unesp.br 
affecting the biodegradability, with degradation taking place preferentially in the polymer amorphous domains (Klun et al., 2003).

Some of these useful biodegradable polymers are poly(vinyl alcohol) (PVA) and poly(caprolactone) (PCL), which can be blended with a synthetic polymer such as poly(vinyl chloride) (PVC) to facilitate their biodegradation in the environment.

Poly (vinyl alcohol) (PVA), a water soluble synthetic polymer prepared by the hydrolysis of polyvinyl acetate, is widely used in adhesives, paper-coating, textiles, wood and furniture, tannery, paints, agro-industries and in biodegradable polymer products. It is a semicrystalline polymer whose crystallinity index depends on the synthesis process and on physical aging. Hydrogen bonds bind the polymer chains together, even in the amorphous phase, and the glass transition and melting temperature of PVA are 85 and $240{ }^{\circ} \mathrm{C}$, respectively (Chandra et al., 1998; Dibbern-Brunelli et al., 1998). The molecular weight of PVA is its most important feature, affecting its crystallinity, adhesion, mechanical properties and diffusion (Kesel et al., 1999). The basic properties of these materials are strongly dependent on the degree of polymerization and hydrolysis, the distribution of hydroxyl groups, and the stereoregularity and crystallinity of PVA. Thus, the evaluation of relationships between the polymer's biodegradability and structure is also of the utmost importance (Solaro et al., 1998).

PCL, a semicrystalline linear aliphatic polyester, is known for its biocompatibility and biodegradability, which make it a useful material in resorbable sutures, drug delivery systems, and more recently in bone graft substitutes (Peña et al., 2006). Moreover, PCL - one of the most hydrophobic of commercially available biodegradable polymers - has good mechanical properties and is compatible with many types of polymers (blends, blocks), which broadens its range of applications (Amass et al., 1998; Peña et al., 2006; Albertsson et al., 1996).

PVC as well as three other major plastics, i.e., polyethylene (PE), polypropylene (PP) and polystyrene (PS), are used worldwide (Kamo et al., 2003). PVC is applied predominantly in the construction sector, and its products are, therefore, highly durable (Mersiowsky et al., 2001). Several polymers are currently mixed with PVC to alter the latter's properties, such as its high impact strength, heat resistance and processability (Karal et al., 1997).

It is important to mix (blend) the polymers to obtain a matrix with good mechanical properties and which is suitable for disposal in the environment (Amass et al., 1998). Some of the factors that affect the biodegradation process are the nature of the polymer, the interactions among the blend's components; its crystallinity; and environmental conditions (light, temperature, $\mathrm{O}_{2}$ concentrations; and humidity) (Lucas et al., 2008). Therefore, the aim of this study was to investigate the biodegradation of PVA/PVC and PVA/PCL blend films in the landfill leachate by respirometry, contact angle measurements, spectrophotometric analyses and scanning electron microscopy (SEM).

\section{MATERIALS AND METHODS}

\section{Preparation of films}

PVA (Hanil Brasil - Polinol- P-05, Mø: 70,000100,000 g/mol; $\mathrm{Tg}: 85^{\circ} \mathrm{C}$, degree of hydrolysis 86.1\%), PVC (Sigma-P-9401, Mळ: 73,491g/mol) and PCL (Solvay-K6800, Mळ: 85,000 g/mol) were used for this work. Homopolymer films were prepared by dissolving the predetermined weights of each polymer $(0.2 \mathrm{~g})$ in $8.0 \mathrm{~mL}$ of $\mathrm{N}-\mathrm{N}$ dimethylformamide (DMF) at $80^{\circ} \mathrm{C}$ for $1 \mathrm{~h}$ and vacuum evaporating the final solutions at $65^{\circ} \mathrm{C}$ and $500 \mathrm{mmHg}$ in stainless steel dishes. The films were then vacuum-dried for two days at room temperature.

The blend films were prepared by mixing the two polymers $(0.2 \mathrm{~g}$ in total, PVA/PCL $4: 1, \mathrm{w} / \mathrm{w})$ at $65^{\circ} \mathrm{C}$ and vacuum evaporating the solvent, following the same procedure as the homopolymer films.

PVA/PVC blend films (1:1, w/w) were obtained as PVA/PCL films, but were solubilized separately in the first 15 minutes, after which the solutions were mixed and shaken for 30 minutes to prevent the phase separation. This mixture was then evaporated at $65^{\circ} \mathrm{C}$ and $100 \mathrm{mmHg}$ to produce the blend film. The concentration and quantity of the solution were adjusted to obtain $90-110 \mu \mathrm{m}$ films.

\section{Soil preparation}

Soil was taken from a garden near the Department of Biochemistry and Microbiology (UNESP at Rio Claro, SP, Brazil) and was sifted through a 2-mm 
mesh sieve. Water was mixed into the soil to reach its maximum water-holding capacity, $60 \%$. Half of the wet soil was used directly in the biodegradation experiments and the other half was distributed in respirometer flasks in $50 \mathrm{~g}$ aliquots, To this, $1.0 \mathrm{~mL}$ leachate, taken from the garbage landfill of Piracicaba city (SP, Brazil), was added. The soil and the soil plus with landfill leachate (soil/ leachate) were left unsterilized in order to use live microorganisms for the biodegradation (Campos et al., 2007). The landfill leachate had $\mathrm{pH} 7.0$, and, given its origin, contained a diversity of microbes and heavy metals, but these were not identified by the qualitative analysis.

The soil was subjected to a chemical analysis following the standard methods of the IAC (Campinas Institute of Agronomy) (Van Raij et al., 2001). The soil contained $227 \%$ of organic matter and the mineral particles were $39 \%$ sand, $45 \%$ silt and $16 \%$ clay, with a $\mathrm{pH}$ of 5.9.

\section{Respirometric tests}

PVA, PCL, PVC, PVA/PCL 4:1 and PVA/PVC $1: 1$ films, about $100 \mu \mathrm{m}$ of thickness and $0.2 \mathrm{~g}$ in mass, were buried in the non-sterile garden soil and in the soil with landfill leachate, inside the respirometer (triplicate tests) at $28^{0} \mathrm{C}$ for 120 days The accumulation of $\mathrm{CO}_{2}$ was monitored, following the Brazilian technical standard (ABNT - NBR 14283, 1999). The tests of biodegradation by the respirometry are described in an earlier paper in Campos and co-workers (2007), which gives details of the Brazilian standard (ABNT NBR 14283, 1999). The analysis of the PVA films in the liquid medium was difficult due its solubility, thus to know its concentration after the biodegradation process, it was necessary to apply the same test made to the PVA hydrolysis: spectrophotometric measurement described by Finley (1961).

\section{Determination of PVA concentration after microbial degradation}

The landfill leachate and the soil microorganisms were used as microbial inocula. This leachate was obtained from a landfill in Piracicaba, SP, Brazil and stored at $8{ }^{\circ} \mathrm{C}$, a selection factor for psychrophilic microorganisms (reproduction temperature of 0 to $20^{\circ} \mathrm{C}$ ). The species included Enterobacter cloacae, Yersinia enterocolitica and Hafnia alvei (França-Filho et al., 2006). A common enrichment procedure was adopted to obtain the acclimated inocula. Soil, landfill leachate and PVA were mixed in a ratio of $1 \%$ by weight to $100 \mathrm{~mL}$ of a mineral medium (MM) and shaken for $30 \mathrm{~min}$. The cultures were then incubated at $28{ }^{\circ} \mathrm{C}$ for seven days. After one week, a $2.0 \mathrm{~mL}$ sample of the culture with PVA was transferred into fresh $\mathrm{MM}$ and incubated at $28{ }^{\circ} \mathrm{C}$ for 120 days.

The PVA concentration in the MM was determined quantitatively by the spectrophotometric analysis, after the addition of $3.0 \mathrm{~mL}$ of boric acid and $2.0 \mathrm{~mL}$ of $\mathrm{I}_{2}-\mathrm{KI}$, according to the procedure described by Finley (1961) to $10 \mathrm{~mL}$ of medium containing the solution of PVA and microorganisms. The determination of the PVA concentration was based on a standard curve obtained by measuring the PVA solutions of known concentrations (0.1-10 $\mathrm{mg} / \mathrm{mL})$ after incubation.

\section{PVA Hydrolysis Test}

This analysis was applied to PVA, which was dissolved in the aqueous medium, thus making it difficult to quantify by other techniques. After its microbial treatment in a liquid medium, the concentration of PVA was determined quantitatively as described before. The PVA films were placed in a tube containing $8.0 \mathrm{~mL}$ of phosphate buffer, $\mathrm{pH} 5.6$ (the same $\mathrm{pH}$ as soil) and incubated at $28{ }^{\circ} \mathrm{C}$ for six days. The phosphate buffer was prepared with sterilized tubes and Milli-Q water.

\section{Characterization}

Fourier transform infra-red analysis (FTIR)

The infrared spectra of the polymers and polymeric blends were obtained at room temperature, using a Shimadzu FTIR-8300 spectrophotometer with $4 \mathrm{~cm}^{-1}$ resolution. The PVA/PVC $(1: 1, \mathrm{w} / \mathrm{w})$ blend films could not be analyzed by the FTIR due to surface heterogeneity of film.

\section{Contact Angle Measurements}

The samples of pre- and post-biotreatment films were placed on plain glass plates, on which a drop $(20 \mu \mathrm{m})$ of distilled water was deposited. This drop was illuminated and its image was magnified and projected onto a white screen where the contact angle was measured. The procedure was repeated three times and the mean deviation was calculated from these measurements (Campos et al., 2007). 
Scanning Electron Microscopy (SEM)

The surfaces of the samples were coated with the gold using a Balzers MED 010 sputter coater, after which they were mounted onto a sample holder and their morphology was examined under a scanning electron microscope (Zeiss DSM 940-A), $5 \mathrm{kV}$.

\section{Differential Scanning Calorimetry (DSC)}

The melting behavior of the samples (each weighing approximately $6 \mathrm{mg}$ ) was examined using a TA Instruments DSC2910 differential calorimeter (at IFSC-USP), from 25 to $250{ }^{\circ} \mathrm{C}$ at a heating rate of $10{ }^{\circ} \mathrm{C} / \mathrm{min}$, in a nitrogen atmosphere and at $50 \mathrm{~mL} \cdot \mathrm{min}^{-1}$. The calorimeter was properly calibrated using the indium standard $\left(\mathrm{Tf}=159.11^{\circ} \mathrm{C} ; \Delta \mathrm{H}=30.66 \mathrm{~J} / \mathrm{g}\right)$. The degree of crystallinity of the blends was calculated based on $\Delta \mathrm{H}$ values of $136 \mathrm{~J} / \mathrm{g}$ (Kesel et al., 1999) for $100 \%$ crystalline PCL and $152 \mathrm{~J} / \mathrm{g}$ (Martins-Franchetti et al., 2008) for $100 \%$ crystalline PVA, using the follow equation (Quental et al., 2005).

$$
\chi_{c}=\frac{\Delta H_{f}}{\Delta H_{100 \%}} x 100
$$

\section{RESULTS AND DISCUSSION}

PVA buried in the soil and in the soil with landfill leachate showed significant degrees of biodegradation in relatively short incubation times. In view of this finding, an investigation was made on the influence of PVA polymer properties, such as its degree of hydrolysis, on the rate and extent of biodegradation in the presence of acclimated mixed bacterial culture in the liquid medium and sterile phosphate buffer for the PVA solution. The biodegradation of PVA followed the usual mechanism of polyesters, i.e., hydrolysis of the acetate groups of the PVA chain and oxidation by enzymatic action (Chiellini et al., 2003). This reaction also occurs in PCL chains.

PVC is a strong plastic that resists abrasion and chemicals and has low moisture absorption. Many studies have focused on the thermal and photodegradation of PVC, but few reports are available on PVC biodegradation (Shah et al., 2008). According to Kirbas and co-workers (1999), low molecular weight PVC can be exposed to biodegradation by white-rot fungi. PVC pipes exposed to water microorganisms have shown bacterial attachment and formation of extracellular material on their internal surfaces after 8 weeks (Vess et al., 1993). The total degradation of a polymer chain in the presence of aerobic organisms causes oxidation in the chain, producing $\mathrm{CO}_{2}$ and $\mathrm{H}_{2} \mathrm{O}$ (mineralization) (Martins-Franchetti et al., 2006).

The biodegradation of the films was analyzed based on the evolution of $\mathrm{CO}_{2}$, FTIR, DSC and contact angle measurements. Figures 1-A and 1-B show the evolution of $\mathrm{CO}_{2}$ in the soil and soil with leachate, respectively. It was observed that PVA was more susceptible to the attack of soil microorganisms than the PVC. In the soil, the behavior of the blends differed from that of the PVA, showing less respiration than the PVA and similar to that of the soil. This finding suggested the occurrence of intermolecular interactions between the two polymer chains, which protected the PVA (interactions between the acetate groups of the PVA and the $\mathrm{HC}-\mathrm{Cl}$ of PVC). These interactions occurred at the interface of the two polymers in the amorphous phase, corroborating the findings reported by Kaczmarek (1996). The same tendency was observed in the evolution of $\mathrm{CO}_{2}$ in the soil with leachate (Fig. 1-B).

Among the homopolymers (Fig. 2-A and 2-B), the PVA proved to be more biodegradable than the PCL. The $\mathrm{CO}_{2}$ concentration released in the PVA/PCL (4:1) blend was similar to that of the PCL and lower than PVA, although the PVA concentration in the blend was higher. PCL inhibited the biodegradation of PVA, suggesting specific interactions between the two polymer chains. Therefore, despite the low concentration of the PCL in the blend, its presence played a significant role in protecting the blend, as reported by Arcana and co-workers (2008). This protection was confirmed by the FTIR measurements of the virgin films (Fig. 3), which indicated the changes in the band at $3350 \mathrm{~cm}^{-1}$, assigned to the vibrations of $\mathrm{OH}$ groups in the PVA, and at $1245 \mathrm{~cm}^{-1}$ in the PVA/PCL (4:1) blend, assigned to $\mathrm{C}=\mathrm{O}(\mathrm{O})$ vibrations in the PVA/PCL in relation to the homopolymer spectra.

The curves for the soil containing the leachate (Fig. 2-B) showed the same tendency as the soil without leachate (Fig. 2-A), but the $\mathrm{CO}_{2}$ concentration released was lower, suggesting that the microorganisms in the leachate inhibited the PVA biodegradation. 

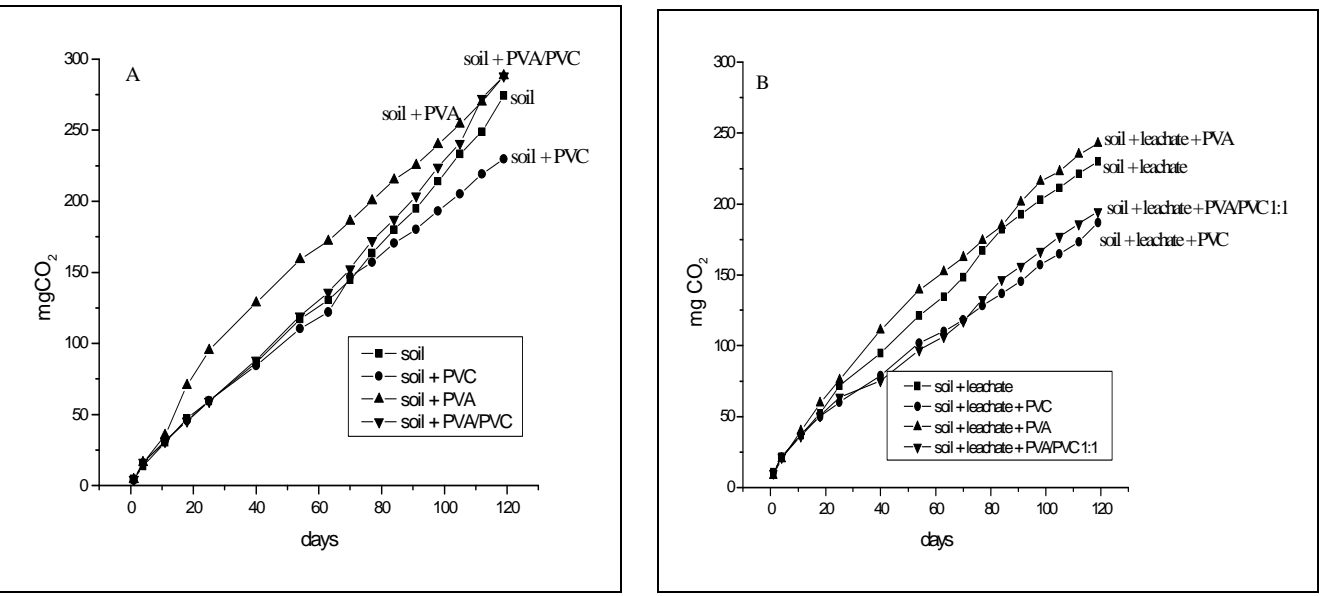

Figure 1 - Biodegradation of PVA, PVC and PVA/PVC (1:1) blends by the evolution of $\mathrm{CO}_{2}$ : Abiodegradation in soil; B- biodegradation in soil with leachate.
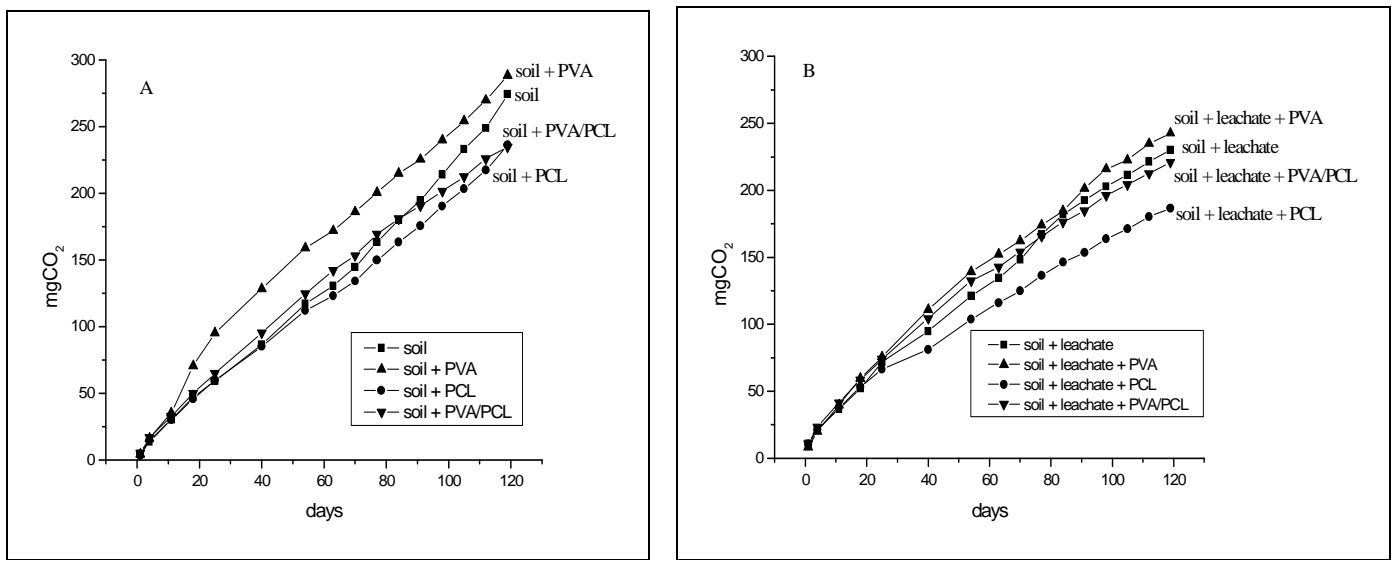

Figure 2 - Biodegradation of PVA, PCL and PVA/PCL (4:1) blends by the evolution of $\mathrm{CO}_{2}$ : Abiodegradation in soil; B- biodegradation in soil with leachate.

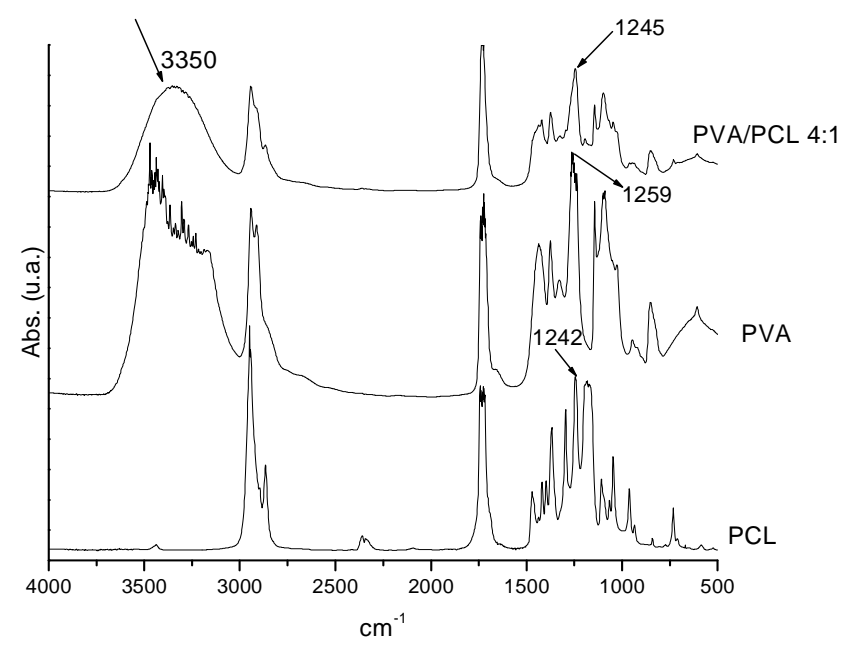

Figure 3 - FTIR spectra of the virgin PVA, PCL and PVA/PCL (4:1) films. 
This protective effect was also suggested by the DSC curves, which showed a decrease in the crystalline fraction of PVA in the blend and a significant increase in the fraction of crystalline PCL in the blend, indicating possible interactions of the $\mathrm{OH}$ group of PVA and the $\mathrm{C}=\mathrm{O}$ of $\mathrm{PCL}$ in the amorphous phase, in agreement with Zhou and co-workers (2004).

The DSC curves of the PVA film showed two peaks, the first indicating the loss of water and the second indicating the melting of the PVA (Fig. 4 and 5).

The PVA/PCL blend showed a decrease in the PVA and an increase in the PCL crystallinity (Table 1), suggesting that the $\mathrm{OH}$ groups of PVA (major composition) in the amorphous phase interacted with the $\mathrm{C}=\mathrm{O}$ of the PCL (minor composition) (Fig. 4 and Table 1).

Some PCL chains underwent reorganization, increasing its crystalline fraction, while others retained the PVA in the amorphous phase. This PVA phase showed preferential biodegradation, as indicated by the evolution of $\mathrm{CO}_{2}$ (Fig. 2).

In the PVA/PVC blend, the interactions between the $\mathrm{OH}$ groups of the PVA and the $\mathrm{H}-\mathrm{C}-\mathrm{Cl}$ of the PVC caused the PVA crystalline fraction to increase (Table 2). The PVC did not reach the melting point due to its predominantly amorphous character.

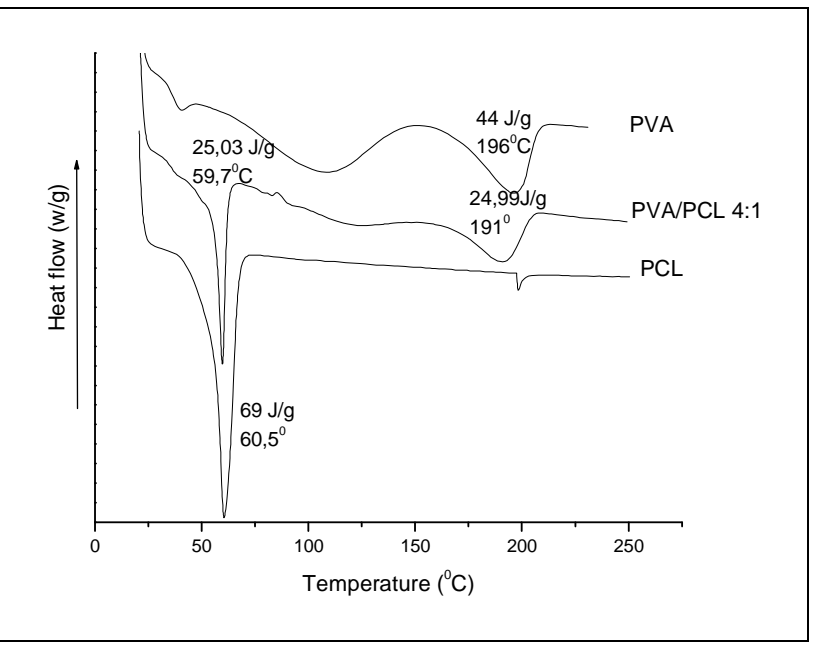

Figure 4 - DSC curves of the virgin PVA, PVA/PCL and PCL films.

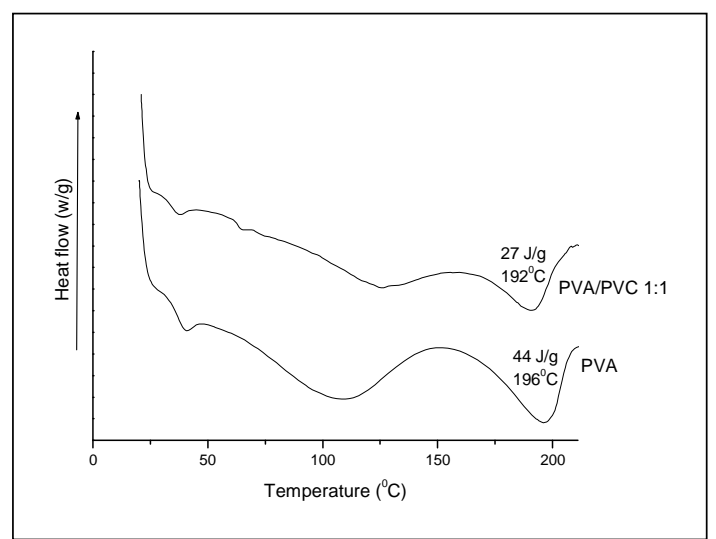

Figure 5 - DSC curves of the virgin PVA and PVA/PVC films. 
Table 1 - Melting point $\left(\mathrm{T}_{\mathrm{m}}\right)$, melting enthalpy $\left(\Delta \mathrm{H}_{\mathrm{m}}\right)$ and percent of crystallinity $\left(\mathrm{X}_{\mathrm{DSC}}(\%)\right)$ of PVA, PCL and PVA/PCL films.

\begin{tabular}{lccc}
\hline Films & $\mathbf{T}_{\mathbf{m}}{ }^{\mathbf{}} \mathbf{C}$ & $\Delta \mathbf{H}_{\mathbf{m}}(\mathbf{J} / \mathbf{g})$ & $\mathbf{X}_{\mathbf{D S C}}(\mathbf{\%})$ \\
\hline Virgin PVA & 196 & 44 & 29 \\
Virgin PCL & 60 & 69 & 50 \\
Virgin PVA/PCL 4:1 & 60 & 25 & $5(\mathrm{a})$ \\
& 191 & 25 & $20(\mathrm{~b})$ \\
\hline
\end{tabular}

Note: (a) PCL, (b) PVA.

Table 2 - Glass transition temperature $(\mathrm{Tg})$, melting point $\left(\mathrm{T}_{\mathrm{m}}\right)$, melting enthalpy $\left(\Delta \mathrm{H}_{\mathrm{m}}\right)$ and percent of crystallinity $\left(\mathrm{X}_{\mathrm{DSC}}(\%)\right)$ of PVC, PVA and PVA/PVC films.

\begin{tabular}{|c|c|c|c|c|}
\hline Films & $\mathrm{Tg}^{0} \mathrm{C}$ & $T_{m}{ }^{0} C$ & $\Delta \mathbf{H}_{m}(J / g)$ & $\mathrm{X}_{\mathrm{DSC}}(\%)$ \\
\hline PVC (o) & 60 & ------- & ------ & ------- \\
\hline PVC in soil (s) & 69 & ------- & ------- & ------- \\
\hline PVC in soil+leachate & 67 & ------- & ------- & ------- \\
\hline PVA (o) & 96 & 196 & 44 & 29 \\
\hline PVA/PVC (o) & 124 & 192 & 27 & 9 \\
\hline
\end{tabular}

The second peak in the PVA/PVC blend shifted to a lower temperature, indicating a reduction of the PVA crystallite size (Fig. 5). In this case, the interaction in the amorphous phase of the two polymers caused the PVA chains to reorganize, thereby decreasing the amorphous phase. Nevertheless, the biodegradation occurred preferentially in the PVA phase rather than in the PVC phase, whose chain contained the $\mathrm{Cl}$ groups that hindered its biodegradation. It was also observed that $\mathrm{Tg}$ of the blend was higher than the homopolymers, indicating the interaction between both. The crystalline fractions of the PVA/PCL $4: 1$ and PVA/PVC 1:1 blends were standardized for the purposes of comparison, considering the composition of each polymer in the blend (Tables 1 and 2).

\section{Determination of the PVA concentration after biodegradation}

PVA degradation was measured based on the PVA concentration after it had undergone the action of the soil microorganisms, leachate microorganisms and the soil with leachate microorganisms in the mineral medium (MM). The PVA-iodine complexes showed interesting properties that depended on the degree of polymerization, saponification and stereoselectivity (Yoshinaga et al., 2004). The PVA concentrations were evaluated by the spectrophotometric analysis at $550 \mathrm{~nm}$. The PVA-iodine complex in Figure 6 revealed a decrease in the absorbance of the PVA concentration in the presence of acclimated mixed culture of the soil, leachate and the soil with leachate.

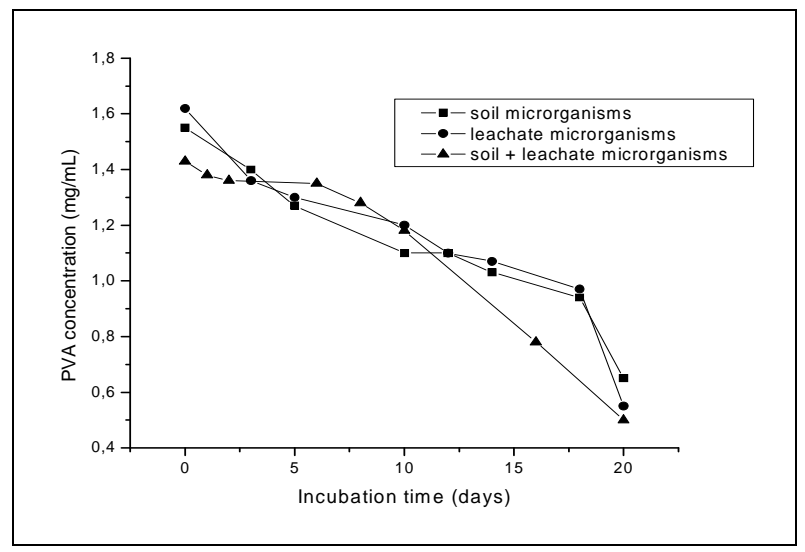

Figure 6 - Variation of PVA concentration recorded in the presence of acclimated mixed culture. 
The considerable degradation of the PVA in the presence of the mixed culture clearly demonstrated that the soil/leachate mixture caused significant degradation, as indicated in a comparison of the two separate treatments, i.e., PVA with the soil microorganisms and PVA with the leachate microorganisms in the MM. Therefore, the mixture of the soil and leachate microorganisms exerted a synergistic effect on the PVA film. According to Kawai (2010), microbial consortia must contribute to the degradation processes in the environment, rather than individual microorganisms, due to metabolic processes, ecological cycles and biological communities.

\section{PVA Hydrolysis}

The PVA in phosphate buffer at pH 5.6 showed no chemical hydrolysis after six days (in the PVA hydrolysis test) (Pezzin et al., 2002). It could, therefore, be stated that the changes were resulted from the treatment in the soil, which caused the biological hydrolysis through the action of microorganisms.

The structure of PVA facilitated the microbiological degradation, as indicated by the evolution of $\mathrm{CO}_{2}$ in the PVA/PCL and PVA/PVC blends, despite the limitations of the respirometric technique. It was found that even in the case of blends with higher crystallinity, the presence of functional groups was more important than the crystallinity, due to the hydrolysis of ester groups, which triggered the biological degradation in the amorphous phase. It is known that the biodegradation is determined by the chemical structure and physicochemical properties and not by their origins, whether natural or artificial (Kawai, 2010).

\section{Contact angle measurements}

The surface properties of the blends were investigated by contact angle measurements. Table 3 showed the results, which were reproducible at \pm $2^{\circ} \mathrm{C}$ in most cases.

The PCL films biotreated in the soil showed a decrease in the contact angle, with no apparent difference when leachate was added. In contrast, the contact angle of PVC films treated in the soil with leachate showed a clearer decrease than in the soil without leachate. The PVA, PCL, PVA/PCL and PVA/PVC were absent from the soil after the biotreatment, indicating they had decomposed. The decrease in the contact angle of the treated films due to the presence of erosion and pits, indicated the adhesion of the microorganisms and probably changes in the roughness after the treatment in the soil.

Table 3 - Water contact angle measurements of PVC, PCL, PVA, PVA/PVC and PVA/PCL.

\begin{tabular}{lcc}
\hline Films & Contact angle & Standard Deviation \\
\hline PVC virgin (o) & $72.3^{\circ}$ & \pm 0.58 \\
PVC soil (s) (120 days) & $49.5^{\circ}$ & \pm 0.7 \\
PVC soil + landfill leachate (120 days) & $44.5^{\circ}$ & \pm 0.7 \\
PCL (o) & $59.5^{\circ}$ & \pm 0.57 \\
PCL (s) (60 days) & $43.5^{\circ}$ & \pm 0.7 \\
PCL soil + leachate (60 days) & $43.5^{\circ}$ & \pm 0.7 \\
\hline
\end{tabular}

\section{Scanning electron microscopy (SEM)}

Figure 7-A shows a SEM image of the surface of the PVC plastic film before the degradation test. Before the tests, the surface of the film displayed interconnected domains resembling the gel structures, indicating the release of solvent
(Martins-Franchetti et al., 2002). The PVC in the soil (Fig. 7-B) showed some cavities and cracks, while the PVC film in the soil with the leachate showed microbial structures similar to the fungal hyphae adhering to its surface (Fig. 8-C). 


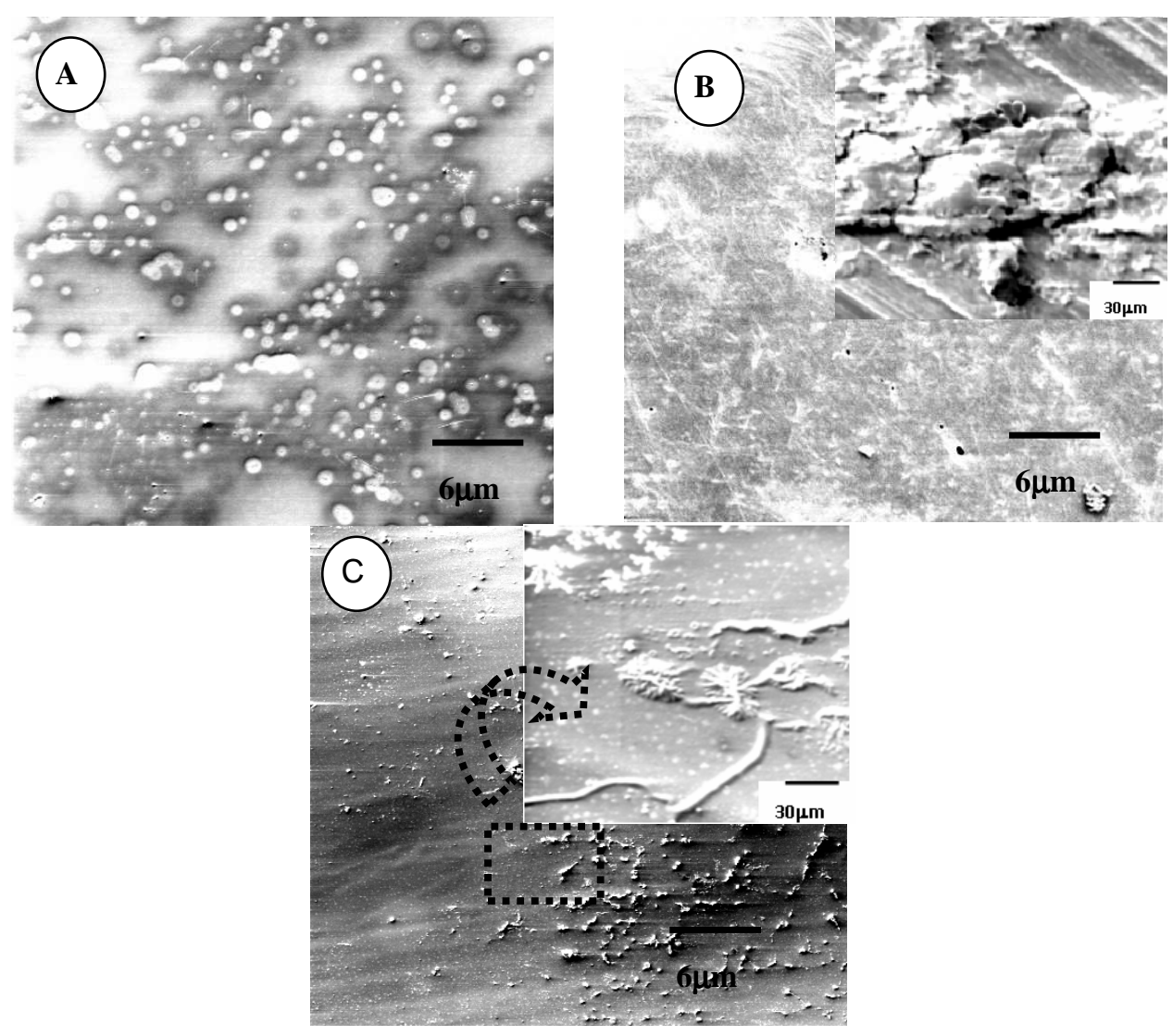

Figure 7 - SEM micrographs of PVC films: A-virgin, B-biotreated in soil for 120 days, and Cbiotreated in soil with leachate for 120 days.

The molecules fragments could be metabolized by the fungi and the craters and erosions on the material surface were the result of microorganisms activity. Since the microorganisms use the polymeric surface components and products of its own metabolism, they release organic acids as metabolites aggressive and esterases, growing deeply in the material, resulting in enlarging the damaged area and thus accentuating the degradation (El-Aghoury et al., 2006). The PCL film (Fig. 8-A) presented a rough surface. After the biotreatment in the soil (Fig. 8-B), the film showed pits and microbial structures adhering to its surface. The polymer film biotreated in the soil with the leachate (Fig. 8-C) displayed pits and microbial structures adhering to its surface. These morphological changes caused by the microbial colonization is one of important factors for the breaking the polymers chains and the biodegradation.

It is known that the enzymatic hydrolysis of biodegradable polyesters proceeds mainly through the mechanisms of surface erosion. The depth and the extent depend on the composition of the micropores of the polymer (TAO et al., 2009).

The PVA film before the biodegradation test is shown in the Figure 9. It had smooth surface with some domains that suggested undissolved crystals (arrows). The PVA/PVC films before the treatment showed the surface with phase separation and domains indicating the release of solvent (Fig. 10). The treatment caused the samples of PVA and PVA/PVC films to degrade and disappear in the soil. 

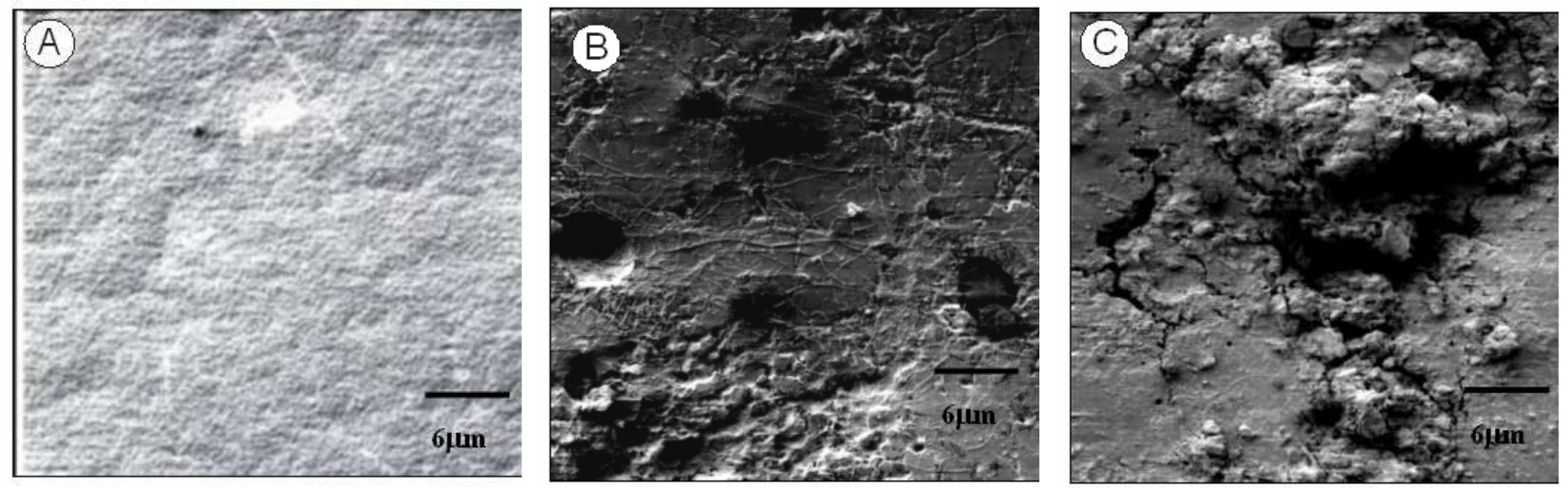

Figure 8 - SEM micrographs of PCL films: A-virgin, B-biotreated in soil for 60 days, and Cbiotreated in soil with landfill leachate for 60 days.

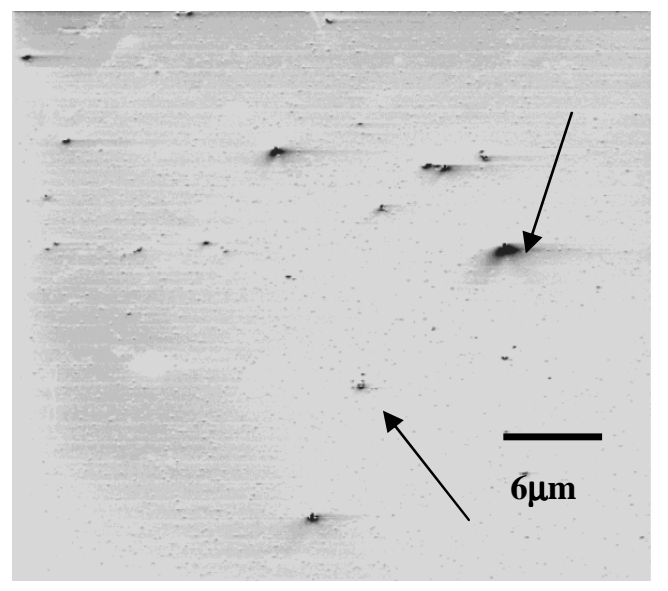

Figure 9 - SEM micrographs of virgin PVA films.

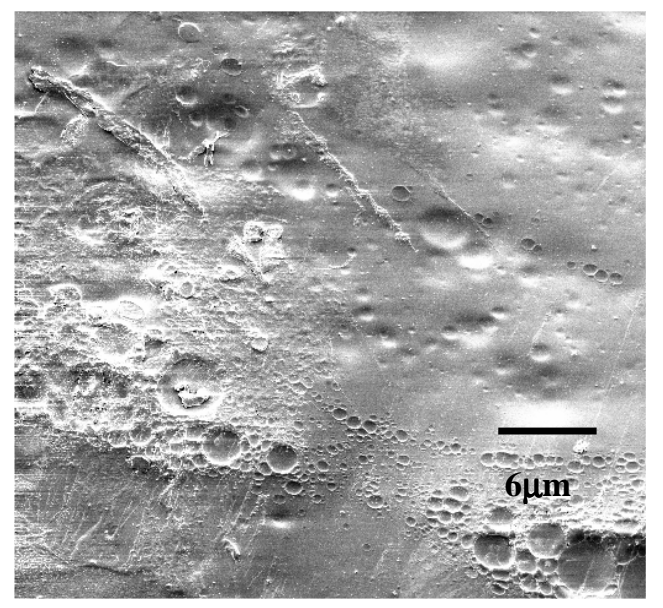

Figure 10 - SEM micrographs of virgin PVA/PVC films. 


\section{CONCLUSIONS}

The respirometric method indicated that the PVA films released more $\mathrm{CO}_{2}$, indicating higher biodegradation than the PCL and PVC. However, in the soil, the PVA/PVC blend showed higher biodegradation than the other polymers. The SEM analysis indicated that the addition of leachate to the soil contributed toward surface changes in the films, causing pits and erosion, but inhibited the evolution of $\mathrm{CO}_{2}$ (biodegradation by the oxidation of the polymer chains). The decrease in the contact angle of the treated films due to the presence of erosion and pits was corroborated by the SEM analysis. The presence of ester groups in the PCL and PVA chains was crucial for the microbiological action, i.e., for the enzymatic hydrolysis of the ester groups. The respirometry, SEM and contact angle techniques indicated that the PVA significantly improved the biodegradation of the blends in the soil, and that the addition of the leachate to the soil inhibited the biodegradation but facilitated the surface erosion of both the blends and homopolymers.

\section{ACKNOWLEDGEMENTS}

The authors acknowledge FAPESP (Brazil) for a doctoral grant (Process no. 04/14381-7)

\section{REFERENCES}

Albertsson, A.C., Karlsson, S. (1996), Macromolecular architecture for degradable polymers. J. Mat. Sci. Pure Appl. Chem. 1571-1579.

Amass, W., Amass, A., Tighe, B. (1998) A review of biodegradable polymers: uses, current, developments in the synthesis and characterization of biodegradable polyester, blends of biodegradable polymers and recent advances in biodegradation studies. Polym. Intern. 47,89-144.

Arcana, I.M., Alio, L. (2008), Polyblends of poly(vinyl alcohol) and poly( $\varepsilon$-caprolactone) and their properties. AIP Conference Proc., 989, 263-267.

Associação Brasileira De Normas Técnicas. Resíduos em solo - Determinação da biodegradação pelo método respirométrico. Norma NBR 14283. São Paulo, 1999.

Campos, A., Martins-Franchetti, S.M., Marconato, J.C., Agnelli, J.A.M., Monteiro, M. (2007), Biodegradation of blend films in soil and soil with chorume. I. PVC/PCL Res. J. Biotech 2, 20.
César, M.E.F., Mariani, P.D.S.C., Innocentini-Mei, L.H., Cardoso, E.J.B.N. (2009), Particle size and concentration of poly(3-caprolactone) and adipate modified starch blend on mineralization in soils with differing textures. Polymer Testing, 28, 680-687.

Chandra, R., Rustgi, R. (1998), Biodegradable Polymers. Progress. Polym. Sci. 23, 1273-1335.

Chiellini, E., Corti, A., D’Antone, S., Solaro, R. (2003), Biodegradation of poly (vinyl alcohol) based materials. Progress. Polym. Sci., 68, 963-1014.

Darwis, D., Mitomo, H., Yoshii, F. (1999), Degradability of radiation crosslinked PCL in the supercooled state under various environments. Polym. Degrad. Stabil. 65, 279-285.

Dibbern-Brunelli, D., Atvars, T.D.Z., Joekes, I., Barbosa, V.C. (1998), Mapping phases of poly(vinyl alcohol) and poly(vinyl acetate) blends by FTIR microspectroscopy and optical fluorescence microscopy. J. Appl. Polym. Sci., 69, 645-655.

El-Aghoury, A., Vasudeva, R.K., Banu, D., Elektorowicz, M., Feldman, D. (2006), Contribution to the study of fungal attack on some plasticized vinyl formulations . J. Polym. Environ., 14, 135-147.

Elzein, T., Nasser-Edine, M., Delaite, C., Bistac, S., Dumas, P. (2004), FTIR study of polycaprolactone chain organization at interfaces.J. Colloid Interface Sci., 273, 381-387.

Finley, J.H. (1961), Spectrophotometric Determination of Polyvinyl Alcohol in Paper Coatings. Anal chem 33, 1925-1927.

França-Filho, A.T, Mesquita, A.J., Oliveira, J.P., Bueno, C.P., Lopes, J.H., Couto, M.V., Borges, N.M.F. (2006), Qualidade bacteriológica de meiascarcaças bovinas oriundas de matadouros frigoríficos de Estado de Goiás habilitados para exportação. Ciência Animal Brasileira, 7, 315-325.

Huang, S.J. (1995). J. Mat. Sci. - Pure Appl. Chem., 32, 493.

Kaczmarek, H. (1996), Changes of polymer morphology caused by U.V. Irradiation: 1.Surface damage polymer. Polym. Degrad. Stabil., 37, 189194.

Kamo, T., Kondo, T., Kodera, Y., Sato, Y., Kushiyama, S. (2003), Effects of solvent on degradation of poly(vinyl chloride). Polym, Degrad. Stabil. 81,187169.

Karal, O., Hamurcu, E., Baysal, B.M. (1997), Blends of polycaprolactone - poly dymetylsiloxane) polycaprolactone triblock copolymer with poly (vinyl chloride): preparation and characterization Polym. Degrad. Stabil. 38, 6071-6078.

Kawai, F. (2010), The biochemistry and molecular biology of xenobiotic polymer degradation by microorganisms. Biosci. Biotechnol. Biochem., 74, 1743-1759. 
Kesel, C., Vander Wauven, C., David, C. (1999), Biodegradation of polycaprolactone and its blends with poly(vinyl alcohol) by micro-organisms from a compost of house-hold refuse Polym. Degrad. Stabil., 55, 107-113.

Kirbas, Z., Keskin, N., Güner, A. (1999), Biodegradation of polyvinyl chloride (PVC) by white rot fungi. Bulletin of environmental contamination and toxicology, 63, 335-342.

Klun, U., Friedrich, J., Krzan, A. (2003), Polyamide-6 fibre degradation by a lignolytic fungus. Polym. Degrad. Stabil. 79, 99-104.

Lucas, N., Bienaime, C., Belloy, C., Queneudec, M., Silvestre, F., Nava-Saucedo, J.E. (2008), Polymer biodegradation: mechanisms and estimation techniqyes - A review. Chemosphere, 73, 429-442.

Martins-Franchetti, S.M,, Campos, A., Egerton, T.A., White, J.R. (2008), Structural and morphological changes in Poly(caprolactone)/poly(vinyl chloride) blends caused by UV irradiation. J. Mater. Sci., 43, 1063-1069.

Martins-Franchetti, S.M., Marconato, J.C. (2006), Polímeros biodegradáveis - Uma solução para diminuir a quantidade de resíduos plásticos. Química Nova, 29, 811-816.

Martins-Franchetti, S.M., Muniz, D.K. (2002), Interação entre filmes de PVC e chorume enriquecido com meio mineral. Arq. Inst. Biol., 69, 103-107.

Mersiowsky, I., Weller, M., Ejlertsson, J. (2001), Fate of Plasticised PVC Products under Landfill Conditions: A Laboratory-Scale Landfill Simulation Reactor Study. Water Research, 35, 3063-2070.

Penã, J., Corrales, T., Izquierdo-Barba, I., Doadrio, A.L., Vallet-Regí, M. (2006), Long term degradation of poly( $t_{\text {- }}$-caprolactone) films in biologically related fluids. Polym. Degrad. Stabil., 91, 1424-1432.

Pezzin, A.P., Zavaglia, C.A.C., Duek, E. (2002), Alkaline dechlorination of poly(vinyl chloride) in organic solvents under mild conditions. Polímeros, 12, 285-294.

Pospisil, J. (1999), Degradation and aging of polymers blends. Thermomechanical and thermal degradation. Polym. Degrad. Stabil. 65, 405-414.

Quental, A. C., Hanamoto, L. S., Felisberti, M. I. (2005), Caracterização de polietilenos lineares de baixa densidade II: fracionamento por cristalização isotérmica a partir do estado fundido. Polímeros, 15, 281-288.
Reddy, C.S.K., Ghai, R., Rashmi, R., Kalia, V.C. (2003), Polyhydroxyalkanoates: an overview. Bioresource Technology, 87, 137-146.

Rosa, D.S., Chui Q.S.H., Pantano-Filho R, Agnelli J.M. (2002), Avaliação da Biodegradação de Poli- $\beta$ (Hidroxibutirato), Poli- $\beta$-(Hidroxibutirato-covalerato) e Poli- $\varepsilon$-(caprolactona) em Solo Compostado Polímeros, 12, 311-317.

Shah, A.A., Hasan F., Hameed, A., Ahmed, S. (2008), Biological degradation of plastics: A comprehensive review. Biotechnology Advances, 26, 246-265.

Solaro, R., Corti, A., Chiellini, E. (1998), A new respirometric test simulating soil burial conditions for the evaluation of polymer biodegradation. $J$. Enviromen., 6, 203-208.

Takasu, A., Itou H., Takada, M., Inai, Y., Hirabayashi, T. (2002), Accelerated biodegradation of poly(vinyl alcohol) by a glycosidation of the hydroxyl groups. Polymer, 43, 227-231.

Tao, J., Song, C., Cao, M., Hu, D., Liu, L., Liu, N., Wang, S. (2009) Thermal properties and degradability of poly(propylene carbonate)/poly $(\beta$ hydroxybutyrate-co- $\beta$-hydroxyvalerate) (PPC/PHBV) blends. Polym. Degrad. Stabil., 94, 575-583.

Van Raij., B., Andrade, J.C., Cantarella, H., Quaggio, J.A. (2001), Análise química para avaliação da fertilidade de solos. Instituto Agronômico, 285p.

Vess, R.W., Anderson, R.L., Carr, J.H., Bond, W.W., Favero, M.S. (1993), The colonization of solid PVC surfaces and the acquisition of resistance to germicides by water micro-organisms. J. Appl. Microbiol., 74, 215-221.

Wu, C.S. (2003), Physical properties and biodegradability of maleated-polycaprolactone/starch composite. Polym.Degrad. Stabil. 80, 127-134.

Yoshinaga, T., Yamaye, M., Kito, T., Ichiki, T., Ogata, M., Chen, J., Fujino, H., Tanimura, T., Yamanobe, T. (2004), Alkaline dechlorination of poly(vinyl chloride) in organic solvents under mild conditions. Polym. Degrad. Stabil., 86, 541-547.

Zhou, J., Nishimura, Y., Takasu, A., Inai, Y., Hirabayashi, T. (2004), Morphology and biodegradability of $\operatorname{poly}(\varepsilon$-caprolactone $) /$ poly(vinyl alcohol) block copolymers. Polymer J., 36, 695-704.

Received: March 29, 2010;

Revised: March 02, 2011; Accepted: September 11, 2011. 